\title{
Studies on the Quantitative Autoradiography. I. Radioluminography for Quantitative Autoradiography of ${ }^{14} \mathrm{C}$
}

\author{
Naomi Motoji,* Emiko Hayama, and Akiyo Shigematsu \\ Institute of Whole Body Metabolism, 340-2 Nauchi, Shiroi-machi, Inba-gun, Chiba 270-14, Japan. \\ Received September 1, 1994; accepted October 1, 1994
}

Evidence is presented to elucidate whether or not quantitative analysis of autoradiographs can be obtained with a ${ }^{14} \mathrm{C}$-labelled compound by the use of a new type of radiosensor called Imaging plate (IP). Our results showed that a linear relationship between relative intensity of PSL-BG and radioactivity of a given area was obtained. The linearity was maintained in a relatively wide range from $10^{1}$ to $10^{5} \mathrm{dpm}$ of radioactivity. About 100 times higher sensitivity of the IP than any commercially available $\mathrm{X}$-ray film was demonstrated for not only ${ }^{14} \mathrm{C}$-radioactive standard sources but also experimentally obtained ${ }^{14} \mathrm{C}$-radioactive spots developed on a TLC plate.

Results also showed a linear relationship between relative intensity and radioactivity of the specimens in a very wide range from $10^{1}$ to $10^{5} \mathrm{dpm} / \mathrm{mg}$ after exposure for $7 \mathrm{~d}$. Furthermore, the relationship between PSL-BG and relative exposure (radioactivity $\times$ exposure time) was linear when PSL - BG was from $10^{1}$ to $10^{5}$. In addition to the above properties, a combination of IP and BAS2000, a computerized image display system, was able to completely erase the background prior to use.

Keywords radioluminography; Imaging plate; quantitative autoradiography; ${ }^{14} \mathrm{C}$-emitter; BAS2000

Radioactive tracer techniques are valuable for their excellent sensitivity and versatility. Many kinds of Xray films have been used since they were first used as radiosensors for macroautoradiography (MARG) by Ullberg. ${ }^{1)}$

MARG is one of the widely used radioactive tracer techniques in the study of endogenous reactions occurring in the body, whereby the processes of separation, extraction and purification can be simplified, if not completely omitted. MARG is superior to all other radioactive tracer techniques because it can show the two-dimensional distribution of a radioactive-labelled substance. This technique remains semi-quantitative, however, as long as a radiographic film is used as a radiosensitive material. ${ }^{1-3)}$

There are some problems involved in converting MARG into a fully quantitative method. These are the thickness of the specimen and the characteristics of the radiosensitive material. The quantitativeness of radiographic materials was discussed in detail in our previous reports. ${ }^{4,5)}$

In general, evaluation of the dose dependency of a radiosensitive material, such as a silver halide radiographic film, is based on the proportional increase in the density of developed silver following a certain period of exposure, that is, the product of radioactive dose and exposure time. This relationship is expressed by a density- vs.-exposure time curve at a fixed dose or a density- $v s$.-dose curve at a fixed exposure time. As previously reported, ${ }^{4,5)}$ neither of these curves was found to be linear. In the case of both relationships, linearity was maintained under the conditions of either short exposure periods (below $4 \mathrm{~d}$ ) or low radioactive concentrations (below $0.05 \mu \mathrm{Ci} / \mathrm{g}$ ). It was, however, not maintained under other conditions described in the previous reports. It was suggested that such nonlinearity was due to the nature of the silver halide particles requiring a minimum number of quanta hitting them to produce an image, and that any excess quanta would not result in an increase in density of the recorded image. The result is that silver halide particles located in the superficial upper-layer region would have greater chances of radiation hitting them, reaching the required number at a lower level of exposure than those in the inner region. Consequently, the latter would contribute little to the image density even if they were exposed to radiation for a longer period of time.

The Imaging plate (IP)(Fuji Photo Film Co., Ltd.) is a unique two-dimensional sensor capable of receiving and storing radiant energy, and is composed of a polyester plate coated with fine crystals of photostimulable phosphor $\left(\mathrm{BaFBr}: \mathrm{Eu}^{2+}\right)$. Upon stimulation with a fine laser beam, the stored energy is converted proportionally into luminescent light, photo-stimulated luminescence (PSL). This luminescence is detected by a photomultiplier tube (PMT) and converted into electrical signals. The principle of "radioluminography" as described above is quite different from that of radiography using silver halide. A computerized system for radioluminography, BAS2000 (Fuji Photo Film Co., Ltd.), consisting of an IP and a computer graphic device for image analysis has been developed by Fuji Photo Film Co., Ltd. This system allows for improved quantitativeness of autoradiography over that achievable by currently available X-ray films.

This report studies the quantitativeness of a radioluminographic system in determining the distribution of a radiographic substance. In addition, the effects of the thickness of the radioactive specimen as well as the geometrical distance between the radioactive specimen and the IP, on the quantitativeness were considered.

\section{MATERIALS AND METHODS}

Radioluminography as Opposed to X-Ray Film Photography $^{6-9)}$ The IP is a flexible image sensor in which groups of very small crystals (grain size: about $5 \mu \mathrm{m}$ ) of photostimulable phosphors of barium fluorobromide containing a trace amount of bivalent europium as a 


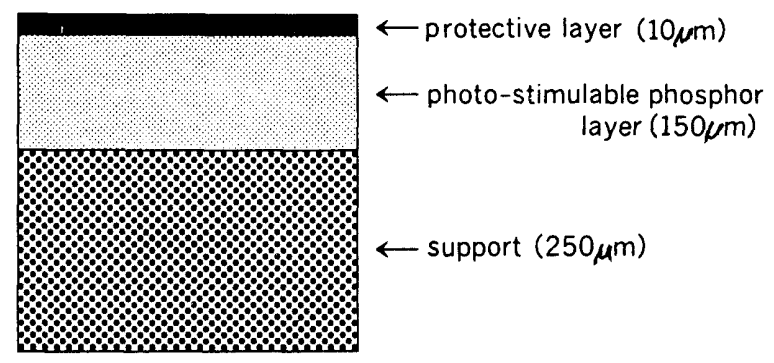

Fig. 1. Schematic of the IP

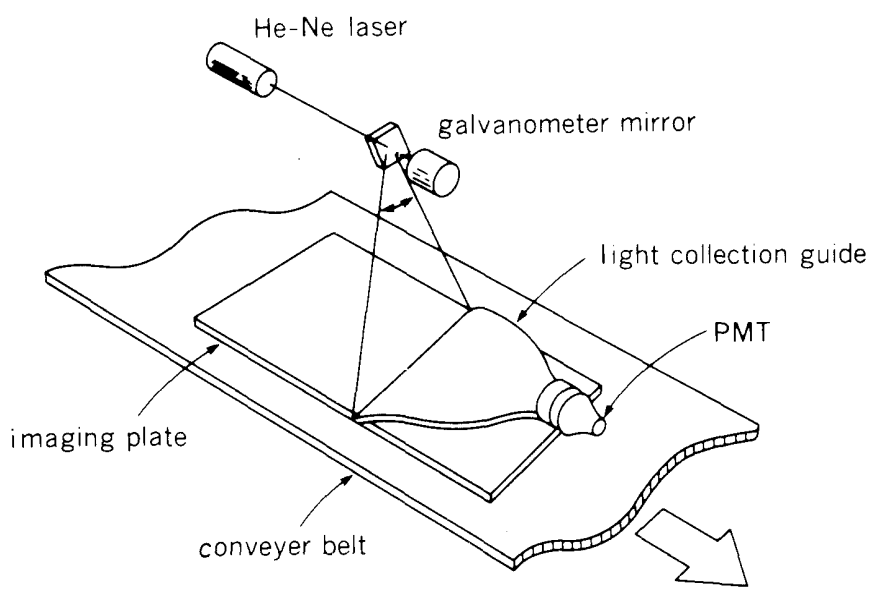

Fig. 2. Principle of Reading the Radiation Image from the IP

The exposed IP, while being conveyed, is scanned with a focused He-Ne laser beam. The PSL released upon the laser irradiation is collected by a PMT through the light collection guide and is converted to electric signals.

luminescence center (formulated as $\mathrm{BaFBr}: \mathrm{Eu}^{2+}$ ), are uniformly coated 150 to $300 \mu \mathrm{m}$ thick on a polyester support film. The schematic of the IP is shown in Fig. 1. In addition to this, a trial IP specially designed for our experiment was fabricated and it is a nonprotectable sensor.

Exposure of samples to the IP is performed in a manner similar to that of X-ray film. ${ }^{10,11)}$ The exposed IP is scanned with a He-Ne laser beam of red light $(633 \mathrm{~nm})$ while the plate is conveyed with high accuracy through a phosphor reader as shown in Fig. 2. Depending on the purpose, the reading density may be selected from 25 to 100 pixels $/ \mathrm{mm}^{2}$. The reading sensitivity and sensitivity range can also be selected based on the objective. A bluish purple $(400 \mathrm{~nm})$ PSL, released upon laser excitation, is collected via the light collection guide and passed through the PMT, where it is converted to analog signals. Subsequently, these are converted to digital signals of 8 to 12 bits, again depending on the intended objective.

Standard Radiation Sources Autoradiographic $\left[{ }^{14} \mathrm{C}\right]$ microscales, PRA511, from Amersham, Inc. were used as ${ }^{14} \mathrm{C}$ standard sources for autoradiography involving radioluminography. The physical and chemical properties of the sources were as follows: density: 1.43, dimensions: $1 \mathrm{~mm} \times 3 \mathrm{~mm} \times 0.12 \mathrm{~mm}$, range of radioactive concentration: $0.1 \mathrm{nCi}(3.7 \mathrm{~Bq}) / \mathrm{g}$ to $100 \mathrm{nCi}(3.7 \mathrm{kBq}) / \mathrm{g}$.

The allowable surface radioactivity of each ${ }^{14} \mathrm{C}$ standard radioactive source, which is obtained by calibration with the self-absorption coefficient, is shown in Table I.
TABLE I. The Surface Radioactivity of Each ${ }^{14} \mathrm{C}$-Standard Radioactive Source

\begin{tabular}{cc}
\hline $\begin{array}{c}\text { Radioactive concentration } \\
(\mathrm{nCi} / \mathrm{g})\end{array}$ & $\begin{array}{c}\text { Surface radioactivity } \\
(\mathrm{dpm})\end{array}$ \\
\hline 0.1 & 0.026 \\
0.2 & 0.051 \\
0.4 & 0.103 \\
1.0 & 0.257 \\
2.0 & 0.514 \\
4.0 & 1.028 \\
8.0 & 2.056 \\
24.0 & 6.167 \\
48.0 & 12.333 \\
101.0 & 25.951 \\
\hline
\end{tabular}

Spacer between the IP and ${ }^{14} \mathrm{C}$ Radioactive Standard Sources Spacers of different thicknesses were fabricated using polyvinylidene chloride films with thicknesses of $1.3,2$ and $4 \mu \mathrm{m}$. The film (density 1.43) was purchased from Mitsubishi Chem. Industry Co., Japan.

Examples of Analytical Specimens: Radioactive-Labelled Compounds D- $\left[\mathrm{U}-{ }^{14} \mathrm{C}\right]$ Glucose $(10.6 \mathrm{GBq} / \mathrm{mmol})$ was purchased from Amersham, Inc.

Thin-layer chromatography (TLC) was carried out by the following procedure. TLC plates made of cellulose, Merck 15275, were used for separating glucose. A solvent system consisting of ethanol, ammonia water and water $(80: 5: 15, \mathrm{v} / \mathrm{v})$ was used for developing the chromatogram.

Preparation of TLC Plates for Separation of Labelled Compounds A series of labelled standard glucose solutions containing 250000, 125000, 62500, 31250, 15625, $7813,3906,1953,977,488,244,122$ and $61 \mathrm{dpm}$ is prepared by simple dilution, without adding nonradioactive glucose, and aliquots on the TLC plates. Ascending chromatography was carried out in a developing chamber with the solvent systems described above.

Radioluminography of TLC Plate and ${ }^{14} \mathrm{C}$ Radiation Standard Source by IP Following chromatography, the plate was kept at room temperature for 2 or $3 \mathrm{~d}$ to evaporate the solvent. The dried TLC plate was wrapped with a thin film of polyvinylidene chloride $(1.3,2$ or $4 \mu \mathrm{m}$ in thickness) to avoid contamination. The plate was then made to contact the IP for a given exposure time. After the exposure, the IP was inserted into the input of a BAS2000 and analyzed. By computed image analysis data, the two-dimensional distribution of radioactivity on the TLC plate was processed, and printed either as a colored or black-and-white hard copy, or digital PSL comparable to the net radioactivity on a defined area of the TLC plate.

\section{RESULTS}

Calibration of PSL by ${ }^{14} \mathrm{C}$ Radioactive Standard Sources Calibration of PSL with ${ }^{14} \mathrm{C}$ radioactive standard sources was undertaken by contacting a trial or a commercial IP with a series of standard sources for 1 , $2,6,24,48$ and $72 \mathrm{~h}$. The effective radiation response indicated by PSL - BG was derived by subtracting the background from the PSL value thus obtained.

Figure 3 shows the relationship between the surface radioactivity of a given standard source and the effective 


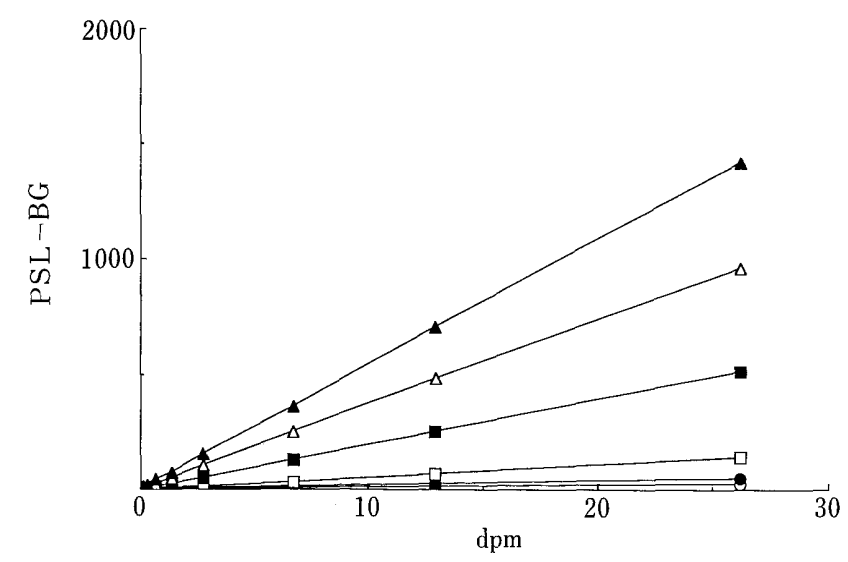

Fig. 3. Relationship between PSL - BG Value of a Trial IP without Protection Layer, versus the Surface Radioactivity of ${ }^{14} \mathrm{C}$ Standard Sources
$\mathrm{O}, 1 \mathrm{~h}$
$\boldsymbol{\bullet}, 2 \mathrm{~h} ; \square, 6 \mathrm{~h} ; \mathbf{\square}, 24 \mathrm{~h} ; \triangle, 48 \mathrm{~h} ; \boldsymbol{\Delta}, 72 \mathrm{~h}$.

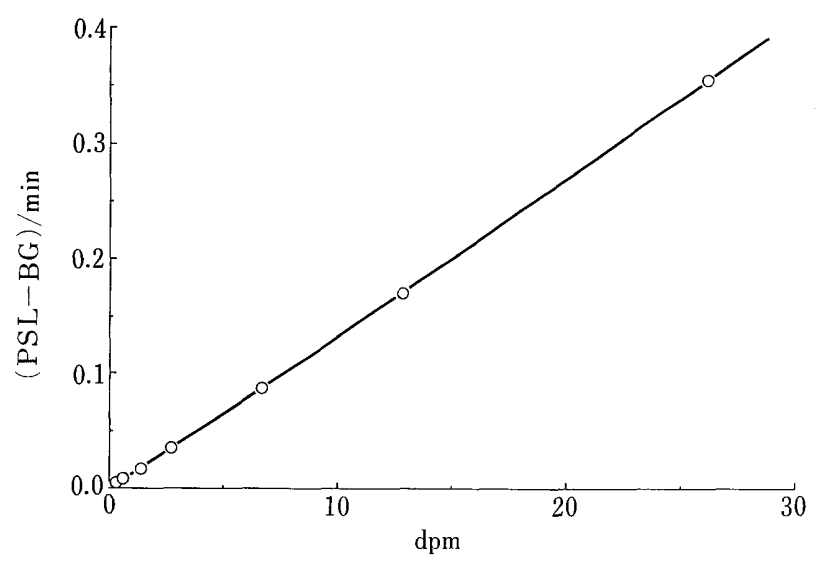

Fig. 4. Sensitivity of IP Estimated by PSL - BG per min versus Radioactivity (dpm) on the Surface of ${ }^{14} \mathrm{C}$ Standard Sources

The relationship of PSL - BG per min to radioactivity (dpm) is linear.

radiation response of a trial IP, without protection layer. A linear relationship was found between the effective radiation response and the radioactive concentration, for all exposure times. Relative intensity per min was calculated and the value was compared to the rate of ${ }^{14} \mathrm{C}$ decay $(\mathrm{dpm})$. A simple linear relationship shown in Fig. 4 was obtained.

The effective radiation responses PSL-BG of a commercial IP (with a $10 \mu \mathrm{m}$-thick protection layer) to the radiation from the sources of various radioactive concentrations were measured. Plastic sheets made of polyvinylidene, ranging from 1.3 to $80 \mu \mathrm{m}$ were used to separate the radioactive source and the IP. Figure 5 shows decreases in PSL - BG values after a 24-h exposure with increase in thickness of the spacer. Because the specially designed trial IP was used, on the $X$ axis showing 0 in thickness of the spacer, each PSL - BG value was in direct proportion to the radioactive concentration of each standard source. Results showed that all of the graphed lines were parallel, indicating the same descending gradient semilogarithmically. It appears, therefore, that a given thickness of the spacer made semilogarithmically reduces the amount of radiation reaching the surface of the IP,

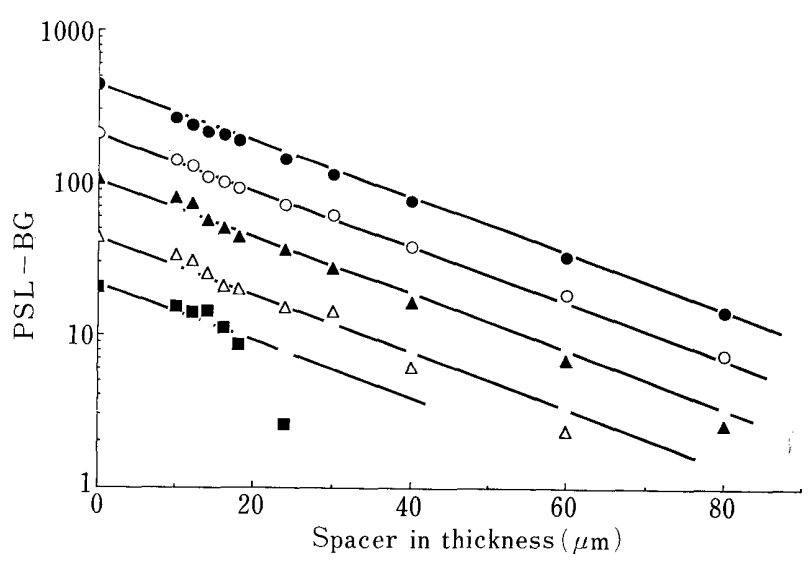

Fig. 5. Decrease in PSL-BG of IP with Spacer Thickness Placed between the IP and ${ }^{14} \mathrm{C}$ Standard Sources after a $24-\mathrm{h}$ Exposure

•, $101 \mathrm{nCi} / \mathrm{g} ; O, 48 \mathrm{nCi} / \mathrm{g} ; \mathbf{A}, 24 \mathrm{nCi} / \mathrm{g} ; \triangle, 8 \mathrm{nCi} / \mathrm{g} ; \mathbf{m}, 4 \mathrm{nCi} / \mathrm{g}$.

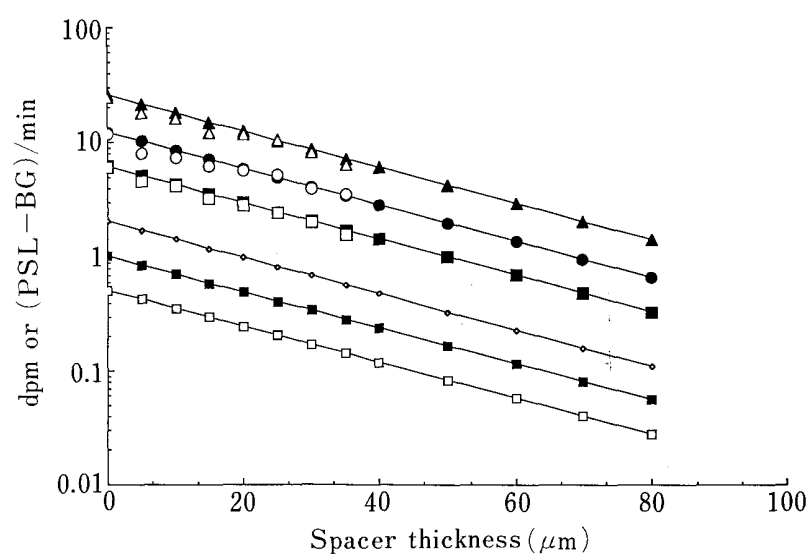

Fig. 6. Decrease in (PSL-BG)/min or Theoretical ${ }^{14} \mathrm{C}$ Radioactivity Reaching the Surface of the IP with Spacer Thickness Placed between the IP and ${ }^{14} \mathrm{C}$ Standard Source after a 24-h Exposure

$-\mathbf{A}-101 \mathrm{nCi} / \mathrm{g} ;--, 48 \mathrm{nCi} / \mathrm{g} ;-\square-, 24 \mathrm{nCi} / \mathrm{g} ;-\diamond-, 8 \mathrm{nCi} / \mathrm{g} ;$
$4 \mathrm{nCi} / \mathrm{g} ;-\square-, 2 \mathrm{nCi} / \mathrm{g} ; \triangle, 101 \mathrm{nCi} / \mathrm{g}^{* *} ; \bigcirc, 48 \mathrm{nCi} / \mathrm{g}^{* *} ; \square, 24 \mathrm{nCi} / \mathrm{g}^{* *}$. $4 \mathrm{nCi} / \mathrm{g} ;-\square-, 2 \mathrm{nCi} / \mathrm{g}$
$* *$ : experimental data.

and the relationship between the PSL-BG and the spacer thickness can be elucidated theoretically.

In order to elucidate the relationship between of the PSL value and the spacer thickness, two radiophysical equations must be provided as follows:

$$
I_{\text {(seif) }}=I_{0} \times\left(l-\mathrm{e}^{-\mu d_{1}}\right) / \mu d_{1}
$$

and

$$
I_{\text {(pass) }}=I_{\text {(self) }} \mathrm{e}^{-\mu d_{2}}
$$

where $I_{0}$ is radioactive concentration $(\mathrm{dpm} / \mathrm{g})$ of the standard source and $I_{\text {(self) }}$ is the radiation intensity on the surface of the standard source with dimensions $0.3 \mathrm{~cm}$ (length) $\times 0.1 \mathrm{~cm} \quad$ (width) $\times 0.012 \mathrm{~cm} \quad$ (thickness depth), which was fabricated from polyethylene containing uniformly radioactive nuclides at a given radioactive concentration. In Eq. 1, $\mu$ is a known absorption coefficient of 0.256 consisting of 2 factors: density of polyethylene material (1.43) and the maximum $\beta$ energy of ${ }^{14} \mathrm{C}$ $(150 \mathrm{keV})$. A value of $0.012 \mathrm{~cm}$ was assigned to $d_{1}$.

As to Eq. 2, each physical value of $\left(d_{2}\right)$ in thickness was calibrated of $\mathrm{mg} / \mathrm{cm}^{2}$ assuming that the density of the spacer, polyvinylidene chloride, is 1.43 , and the maximum 


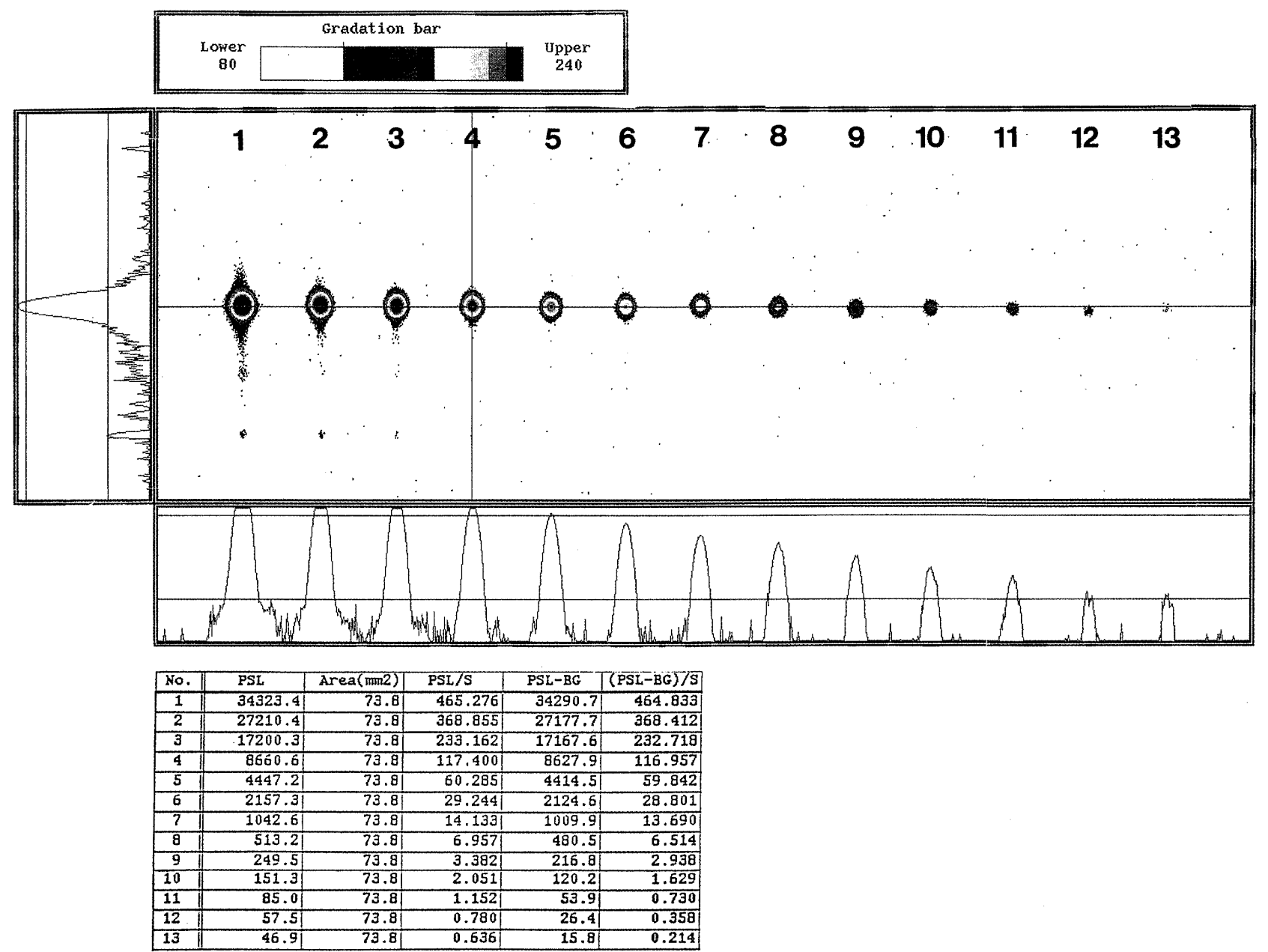

Fig. 7. Colored Hard Copy Displayed by BAS2000 Showing Relative Intensity of Spots on a TLC Plate after Development by a Given Solvent

In the center photo, multicolored spots are displayed along a line from high to low intensity. A green line running horizontally section shows the one-dimensionally extent of relative intensity of each spot. Which is represented by the bottom pictures. A purple line running vertically shows the extent of relative intensity, which is represented the intensity graph on the left.

$\beta$ energy of ${ }^{14} \mathrm{C}$ is $150 \mathrm{keV}, d_{2}$ is a given thickness of the spacer formed by piling the thin film of $1.3 \mu \mathrm{m}$ in thickness.

In general, Eq. 1 is used to calculate for the reduction of radioactive intensity on the surface of the radiation standard source, with consideration of the ${ }^{14} \mathrm{C}$ selfabsorption, as shown in Table I.

In this case, the radioactivity reaching the IP surface decreases at a given rate indicated in Eq. 2, as shown in Fig. 6. By comparing Fig. 5 with Fig. 6, it appears that the gradient of each line in Fig. 5 coincides with that in Fig. 6. Superposing the experimental plots calculated values per min in Fig. 5 upon the corresponding lines in Fig. 6 results in overlapping in most parts, with the exception of the thickness range exceeding $40 \mu \mathrm{m}$ for $24 \mathrm{nCi} / \mathrm{g}$ or less.

MARG of TLC Plates by IP As an example of TLC imaging, a colored hard copy displayed by BAS2000 is shown indicating the relative intensity and the TLC chromatogram. Radioactive specimens were obtained by dilution of $1 \mathrm{mCi} / \mathrm{mmol}\left[\mathrm{U}_{-}{ }^{14} \mathrm{C}\right]$ glucose. Radioactive specimens of $250000,125000,62500,31250,15625,7813$, 3906, 1953, 977, 488, 244, 122 and $61 \mathrm{dpm}$. After development, the plate was made to contact a commercial IP for $3 \mathrm{~h}$. The relative intensity of PSL/spot in relation

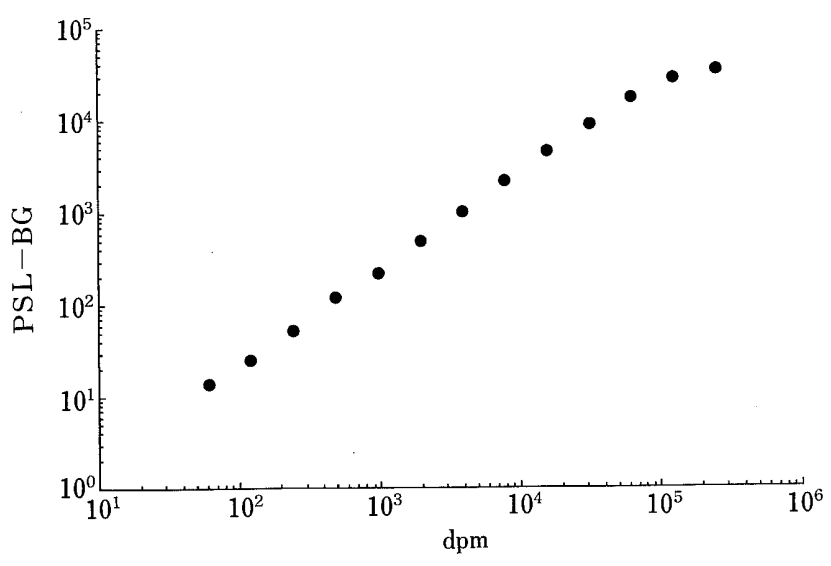

Fig. 8. Relationship of PSL-BG to ${ }^{14} \mathrm{C}$ Radioactivity of Spots after Development on a Cellulose-Plated TLC

The data were obtained from the results in Fig. 7.

to the radioactivity of $\left[{ }^{14} \mathrm{C}\right]$ glucose solution applied to each spot is shown in Fig. 8. A linear relationship was noted. Substantially proportional relation is shown in the range of $10^{2}$ to $10^{5} \mathrm{dpm}$ of the spotted amount where a relative intensity of (PSL-BG) of $2 \times 10^{1}$ to $2 \times 10^{4}$ is 
produced.

\section{DISCUSSION}

The straight lines shown in Fig. 3 without any threshold verify that PSL-BG is proportional to the radioactive concentration. The experimental plots in Fig. 5 overlap with the theoretical plots in Fig. 6, showing theoretically the change in relative intensity with increasing absorption by spacers. This is an additional piece of evidence indicating the proportionality of the PSL $-\mathrm{BG}$ value of IP to the spacer thickness, or the quantitativeness of the PSL system.

Figure 5 shows the experimental data for a trial IP without protection layer, where the lines are extended to an arbitrary thickness of the spacer and serves to determine the net sensitivity of the PSL recording medium with the IP.

Sensitivity is generally represented by a product of the lowest radiation concentration and the shortest exposure time, called relative exposure. In MARG, the amount of exposure is represented by radioactive particles incident on the radiation sensor such as IP, which is the product of the intensity of radiation and the time of exposure. The self-absorption of soft $\beta$ emitters such as ${ }^{14} \mathrm{C}$ and ${ }^{3} \mathrm{H}$ energy must be taken into account when evaluating the quantitativeness of a new autoradiographic sensor.

The intensity of radiation incident upon the autoradiographic sensor is calculated from Eqs. 1 and 2 as shown in the aforementioned results.

The PSL - BG value of 34.7 per 24-h exposure was obtained at $2 \mathrm{dpm}$, emitted from the surface of the ${ }^{14} \mathrm{C}$ standard autoradiographic source of $8 \mathrm{nCi} / \mathrm{g}$ in the case of the trial IP without a protection layer. That indicates a possible calculation of the PSL - BG value based on the radioactivity $(\mathrm{dpm})$ using the following equation, the result of which is shown in Fig. 4.

$N$ radioactivity $(\mathrm{dpm})=(\mathrm{PSL}-\mathrm{BG})$ value/exposure time $(\min ) \times 83$

Quantitativeness of the IP was demonstrated by a set of autoradiographic ${ }^{14} \mathrm{C}$ standard sources as described above. It must be noted, however, that a relatively fine resolution is necessary to differentiate one radioactive point from another for the practical analysis of macroautoradiographic data. Therefore, the quantitative- ness must be examined using point sources, or at least using a specimen containing radioactive spots. The proportionality of PSL-BG value to the amount of radioactive substance on a given spot on the TLC plate was estimated by comparison of the image analysis data obtained from the TLC plate after development where in, $\left[\mathrm{U}-{ }^{14} \mathrm{C}\right]$ glucose was used for this purpose. Assuming that the radioactive concentration of the developed spots on a TLC plate is proportional to the amount of labelled substance spotted on the plate, results indicated that the PSL $-B G$ value of an IP to ${ }^{14} \mathrm{C}$-radioactivity on the plate was proportional to the radioactive concentration on the TLC plate after development.

As shown in Fig. 8, a nonlinear correlation between PSL - BG and the radioactive concentration on the TLC plate was found at some points on the line: one was obtained from the lowest radioactive concentration $(50 \mathrm{dpm})$ at the shortest exposure time $(3 \mathrm{~h})$; the other was from the highest radioactive concentration $\left(1.05 \times 10^{5}\right.$ $\mathrm{dpm}$ ) at the same exposure time. The deviation might be attributed to the too low radioactivity of the background level or the too high radioactivity at a particular pixel.

Acknowledgment We are grateful to Ms. Yuko Hamai for technical assistance.

\section{REFERENCES}

1) S. Ullberg, Acta Radiol. Suppl., 1, 1 (1954).

2) R. H. Hertz, Abstracts of Papers, XIth International Congress of Radiology, 2, 1472 (1961).

3) A. Shigematsu, Igaku No Ayumi, 32, 574 (1960).

4) N. Motoji, E. Hayama, Y. Hatori, A. Shishido, A. Shigematsu, Yakubutsu Dotai, 3, 181 (1988).

5) N. Motoji, Yakubutsu Dotai, 4, 199 (1989).

6) M. Sonoda, M. Takano, J. Miyahara, H. Kato, Radiology, 148, 833 (1983).

7) K. Takahashi , J. Miyahara, Y. Shibahara, J. Electrochem. Soc., 132, 1492 (1985)

8) Y. Amemiya, J. Miyahara, Nature (London), 336, 89 (1988).

9) Y. Amemiya, K. Wakabayashi, H. Tanaka, Y. Ueno, J. Miyahara, Science, 247, 164 (1987).

10) P.B. Gahan, "Autoradiography for Biologists," ed. by P. B. Gahan, Academic Press, London, 1972, p. 19.

11) H. Shindo, "Autoradiography for Visual to Ultramicro Objectives," ed. by B. Mizuhira, City Medical \& Dental Press, Tokyo, 1979, p. 27. 